\title{
3 Researc Square

\section{Diel Activity Patterns of Two Distinct Populations of Aedes Aegypti in Miami, FL and Brownsville, TX}

John-Paul Mutebi ( $\square$ grv0@cdc.gov )

Centers for Disease Control and Prevention

André Barretto Bruno Wilke

University of Miami

Erik Ostrum

Centers for Disease Control and Prevention

Chalmers Vasquez

Miami-Dade County Mosquito Control Division

Gabriel Cardenas

University of Miami

Augusto Carvajal

Miami-Dade County Mosquito Control Division

Maday Moreno

Miami-Dade County Mosquito Control Division

William D. Petrie

Miami-Dade County Mosquito Control Division

Arturo Rodriguez

City of Brownsville - Public Health

Henry Presas

City of Brownsville - Public Health

Jesus Rodriguez

City of Brownsville - Public Health

Fred Barnes

City of Brownsville - Public Health

Gabriel L. Hamer

Texas A\&M University

Jose Juarez

Texas A\&M University

Christopher J. Vitek

The University of Texas Rio Grande Valley

John C. Beier

University of Miami 


\section{Research Article}

Keywords: Mosquito Control, Arboviruses, Dengue, Zika, Surveillance

Posted Date: November 15th, 2021

DOI: https://doi.org/10.21203/rs.3.rs-1040920/v1

License: (c) (i) This work is licensed under a Creative Commons Attribution 4.0 International License. Read Full License

Version of Record: A version of this preprint was published at Scientific Reports on March 29th, 2022. See the published version at https://doi.org/10.1038/s41598-022-06586-w. 


\section{Abstract}

The diel biting activity of Aedes (Stegomyia) aegypti $(\mathrm{L})$ populations was extensively investigated in the early 1900 s to gain more information on the biology of Ae. aegypti, and this information was used to devise effective approaches to controlling populations of this species and protect the human population from widespread arbovirus outbreaks. However, few contemporary studies are available regarding the diel activity patterns of Ae. aegypti. To assess the diel activity patterns of Ae. aegypti in southern Florida and Texas, we conducted 96-hour uninterrupted mosquito collections once each month from May through November 2019 in Miami, Florida, and Brownsville, Texas, using BG-Sentinel 2 Traps. The overall diel activity pattern in both cities was bimodal with morning and evening peak activity between 7:00 and 8:00 and between 19:00 and 20:00. There were significant daily, monthly, seasonal, and site-specific differences in activity patterns, but these differences did not affect the overall peak activity times. These differences suggest daily, monthly, seasonal, and site-specific variations in human exposure to $A e$. aegypti. Our observations can be used in planning and executing Ae. aegypti vector control activities in southern Florida and Texas, especially those targeting the adult mosquito populations.

\section{Introduction}

The diel biting activity of Aedes (Stegomyia) aegypti (L) populations was extensively investigated in the early part of the 20th Century. The primary aim was to gain more information on the biology of $A e$. aegypti and use this information to devise effective approaches to controlling populations of this species and protect the human population from widespread urban yellow fever (YF) outbreaks. The bulk of the investigations were conducted in the tropical regions of South and Central America, and East and West Africa. Most of the early studies and the observations were summarized in the monograph by Christophers $^{1}$. The general observations were that $A e$. aegypti activity was diurnal and it was widely referred to as a daytime biting mosquito ${ }^{1}$. However, there were several studies that detected substantial nighttime biting activity in some populations of Ae. aegypti. For example, Lumsden ${ }^{2}$ reported that approximately $34 \%$ of the Ae. aegypti population in the Southern Province of Tanganyika, in East Africa, were biting at night. In addition, distinct after-dark biting activity peaks were observed indoors but not outdoors ${ }^{2}$ suggesting behavioral adaptations of Ae. aegypti populations to local environmental conditions. Taken together these observations suggested variations in diel host-seeking activity among geographic populations of Ae. aegypti.

Later studies in Tanzania reported that the diel biting activity had two peaks, one in the morning and one in the evening ${ }^{3}$. Similarly, a study in Trinidad detected morning and evening peaks however, this study also detected a third peak at 11:00 ${ }^{4}$. This suggested a trimodal pattern of Ae. aegypti diel biting activity in Trinidad. The study by Diarrassouba and Dossou-Yovo ${ }^{5}$ pointed out that although the biting activity of Ae. aegypti is diurnal in East Africa, the peak biting activity was usually at sunset in West Africa. Furthermore, they reported an unusual diel biting activity in the savannah zone of Côte d'Ivoire in the dry season where Ae. aegypti showed an atypical biting activity rhythm in the dry season, and biting activity 
was throughout the night and peaking at midnight ${ }^{5}$. A recent study by Ortega-López et al. ${ }^{6}$ used BG-Sentinel traps and Mosquito electrocuting traps to study host-seeking activity of Ae. aegypti in Quinindé, Ecuador. They found that female Ae. aegypti had bimodal patterns of host-seeking with a peak in the early morning and another peak in the late afternoon.

There have been very few studies in the contiguous United States (CONUS), and to our knowledge, the only published study from the CONUS is that by Smith et al. ${ }^{7}$. This study was conducted in Saint Augustine, Florida and determined that the evening activity was the most significant, with peak activity occurring between 17:00 and 19:00, followed by a period of substantial host-seeking activity between 19:00 and 21:00. They also detected a minor peak between 7:00 and 9:00. They noted that there was a gradual increase in activity leading up to the peaks and a gradual decrease in activity from the peak hours.

Following the Zika outbreak in the United States in 2016, there was a realization that not much was known about the distribution and the diel host-seeking activity patterns of Ae. aegyptipopulations in the CONUS. In 2019, we initiated a study with the aim to increase our understanding of the diel host-seeking activity patterns of Ae. aegypti in two cities in the southeastern United States. An understanding of the host-seeking diel patterns of mosquitoes can greatly improve the effectiveness of mosquito control by guiding adulticiding and other integrated mosquito control activities.

\section{Results}

\section{Mosquito Species Captured}

A total of 26 mosquito species were collected, 17 species in Brownsville, TX and 18 in Miami, FL (Table 1). The most frequently captured species at both sites was Ae. aegypti, $61.33 \%(13,033 / 21,252)$ of the collection in Brownville, TX, and 48.74\% $(6,461 / 13,257)$ of the collections in Miami, FL. This is not surprising because the BG-Sentinel 2 traps we used in this study were specifically designed to capture $A e$. aegypti $^{8,9}$. The second and third most captured species captured in Brownsville, TX, were Culex (Culex) quinquefasciatus Say, 24.55\% (5,217/21,252), and Aedes (Aedimorphus) vexans (Meigen), 5.39\% $(1,145 / 21,252)$, respectively. In Miami, FL, Wyeomyia (Wyeomyia) vanduzeei Dyar \& Knab $19.94 \%$ $(2,644 / 13,257)$ and Aedes (Ochlerotatus) taeniorhynchus (Wiedemann) $19.93 \%(2,642 / 13,257)$, were the second and third most captured species respectively (Table 1). Of the 26 species captured, only 9 , (34.62\%) were captured in both Brownsville and Miami (Table 1). Six species were unique to the Brownsville collections, and 9 species were captured only in Miami (Table 1). 
Table 1

Mosquito species captured by using BG-Sentinel 2 traps during Aedes aegypti activity pattern studies in Brownsville, Texas and Miami, Florida in 2019.

\begin{tabular}{|c|c|c|c|c|c|c|}
\hline \multirow[t]{2}{*}{ Species } & \multicolumn{3}{|c|}{ Brownsville } & \multicolumn{3}{|c|}{ Miami } \\
\hline & Females & Males & Total & Females & Males & Total \\
\hline Aedes aegypti & 7024 & 6009 & 13033 & 4444 & 2017 & 6461 \\
\hline Aedes albopictus & 424 & & 424 & 1 & & 1 \\
\hline Aedes infirmatus & 395 & & 395 & 2 & & 2 \\
\hline Aedes sollicitans & 58 & & 58 & & & \\
\hline Aedes taeniorhynchus & 420 & & 420 & 2580 & 62 & 2642 \\
\hline Aedes thelcter & 12 & & 12 & & & \\
\hline Aedes tortilis & & & & 629 & & 629 \\
\hline Aedes triseriatus & & & & 6 & 1 & 7 \\
\hline Aedes vexans & 1145 & & 1145 & & & \\
\hline Aedes zoosophus & 1 & & 1 & & & \\
\hline Anopheles atropos & & & & 1 & & 1 \\
\hline Anopheles crucians & & & & 12 & & 12 \\
\hline Anopheles pseudopunctipennis & 27 & & 27 & & & \\
\hline Anopheles quadrimaculatus & & & & 18 & & 18 \\
\hline Culex biscaynensis & & & & 14 & 16 & 30 \\
\hline Culex coronator & 332 & & 332 & 194 & 23 & 217 \\
\hline Culex erraticus & 9 & & 9 & 8 & & 8 \\
\hline Culex nigripalpus & 113 & & 113 & 91 & 6 & 97 \\
\hline Culex quinquefasciatus & 4473 & 744 & 5217 & 237 & 175 & 412 \\
\hline Culex spps & & & & 1 & 3 & 4 \\
\hline Deinocerites cancer & & & & 16 & & 16 \\
\hline Psorophora ciliata & 1 & & 1 & & & \\
\hline Psorophora columbiae & 33 & & 33 & 42 & 3 & 45 \\
\hline Psorophora cyanescens & 28 & & 28 & & & \\
\hline
\end{tabular}




\begin{tabular}{|c|c|c|c|c|c|c|}
\hline \multirow[t]{2}{*}{ Species } & \multicolumn{3}{|c|}{ Brownsville } & \multicolumn{3}{|c|}{ Miami } \\
\hline & Females & Males & Total & Females & Males & Total \\
\hline $\begin{array}{l}\text { Toxorhynchites rutilus } \\
\text { septentrionalis }\end{array}$ & 4 & & 4 & & & \\
\hline Wyeomyia mitchellii & & & & 11 & & 11 \\
\hline Wyeomyia vanduzeei & & & & 2639 & 5 & 2644 \\
\hline
\end{tabular}

\section{Diel activity patterns}

The site-specific diel activity patterns for Ae. aegypti populations in Miami, FL and Brownsville, TX are summarized in Figure 1 and Figure 2, respectively. Data analysis showed significant differences in the $A e$. aegypti diel activity patterns within trap locations and within seasons (Table 2, Figures 1, 2, 3). However, these variations did not affect the overall diel activity patterns within the cities (Figure 4). Overall, Ae. aegypti activity was continuous throughout the day and throughout the night with significantly elevated activity peaks in the mornings and the evenings (Figures 1, 2, 3, 4). The morning peaks were between 7:00 and 8:00 in both Miami, FL and Brownsville, TX (Figure 4). The evening peaks were between 19:00 and 20:00 in both Miami, FL and Brownsville, TX (Figure 4). Multivariate analysis indicated that both morning and evening peaks were significant: Peak Start Time $P$-value $=0.043$, Peak Max $P$-value $=0.006$, suggesting consistent elevated activity at these times. In addition, the multivariate analysis indicated that the morning peak was significantly different between cities; the peak in Brownville, TX was significantly higher than that in Miami, FL $(P$-value $=0.001)$ (Figure 4$)$.

Table 2

Results of the GLIMMIXED regression with a generalized Poisson estimator and log link to assess the effect of geographic location, seasonality, and time in the diel activity of Ae. aegypti.

\begin{tabular}{|lll|}
\hline Covariate & $\boldsymbol{F V}$ Value & $\boldsymbol{P r} \boldsymbol{P} \boldsymbol{F}$ \\
\hline City & 1.73 & 0.1894 \\
\hline Season & 5.71 & $\mathbf{0 . 0 0 3 8}$ \\
\hline City(Season) & 49.22 & $<.0001$ \\
\hline Area(City*Season) & 7.74 & $<.0001$ \\
\hline Time & 48.62 & $<.0001$ \\
\hline
\end{tabular}

\section{Discussion}

Our results show that the average diel activity patterns of Ae. aegypti populations in both Miami, FL and in Brownsville, TX were very similar; they both had two peaks, one in the early morning and the other in 
the evening, and the average host-seeking peaks are between 7:00 and 8:00 and between 19:00 and 20:00 (Figure 4). Similar observations were previously reported by several investigators $3,4,10,11,12$ and the bimodal diel activity pattern is the most frequently reported for Ae. aegypti populations worldwide. However, variations between peak activity have been detected between populations. In East Africa, for instance, Trpis et al. ${ }^{3}$ reported peak activity at 7:00 and at 19:00, whereas McClelland ${ }^{10}$ reported peak activity two or three hours after sunrise (9:00 or 10:00) and one or two hours before sunset (17:00 or 10:00). Similarly, in the United States, Smith et al. ${ }^{7}$ observed a bimodal diel activity pattern for $A e$. aegypti, but the evening peak was earlier, between 17:00 and 19:00. Despite these variations, the spacing of the peaks is similar in all these studies despite the fact that these studies were conducted in ecologically and climatically diverse locations.

The activity patterns observed at site 3 in Brownsville (Figure 2) and at site 1 in Miami (Figure 1) were trimodal. In Brownsville, the trimodal activity peaks were between 6:30 and 7:30, 9:30 and 10:30, and 18:30 and 19:30 (Figure 2), and in Miami the trimodal peaks were between 7:00 and 8:00, 9:00 and 10:00 and between 19:00 and 20:00 (Figure 1). Interestingly, the timing of the third peak was similar in both Brownsville site 3 and Miami site 1 suggesting similar underlying factors despite geographic distance, different ecology, and different climate. Brownsville, Texas, is in the Lower Rio Grande Alluvial Floodplain ecoregion. The climate is humid subtropical and urbanization has removed most of the indigenous palm trees and floodplain forests vegetation (https://www.epa.gov/sites/default/files/2018-

05/documents/brownsvilletx.pdf). Miami is in the Tropical Florida Ecoregion. Similar to Brownsville, Texas, urbanization and agriculture has replaced most of the indigenous Pine Rockland vegetation. Trimodal biting patterns for Ae. aegypti have been observed before in Trinidad by Chadee and Martinez 4 , but the middle peak was observed at 11:00 which is half an hour to an hour later than what we observed in Miami and Brownsville, respectively (Figures 1 and 2). While the morning and evening peaks coincide with human outdoor activity, the middle peak occurs during high heat conditions and the factors that lead to this peak or its importance in the epidemiology of Ae. aegypti-borne arboviral diseases are currently not known. The studies by McClelland ${ }^{13}$ observed multiple activity peaks in an East African population of Ae. aegypti. The significance of the different activity patterns to the epidemiology of Ae. aegypti-borne arboviral diseases are currently unknown and we think they need more investigation especially since $A e$. aegypti-borne arboviral infections have been rising in the recent past ${ }^{14,15}$.

We observed that the host-seeking activity peaks were consistent between 5:45 and 7:30 and between 18:00 and 20:45 (Figures 1 and 2). These observations are important in planning and conducting control operations directed at the adult Ae. aegypti female populations. During the 2016 Zika outbreak, there was no specific information on the host-seeking activity patterns of Ae. aegypti in Miami Dade County and the adulticide treatment implemented as part of an integrated approach targeted the morning activity ${ }^{16}$. The integrated approach effectively reduced the vector population and interrupted the transmission of the Zika virus; however, it highlighted the need for site-specific information on the diel activity patterns of $A e$. aegypti in Miami Dade County in particular and the CONUS in general. There have been sporadic Ae. aegypti-borne arboviral disease outbreaks in Miami Dade County, FL and the city of Brownsville, TX ${ }^{17-21}$, 
in the future we will be better prepared to conduct effective adulticide applications with the current knowledge of the diel activity patterns of Ae. aegypti in these areas. Furthermore, we are now better equipped to educate the public on how to minimize exposure to Ae. aegypti-borne arboviral diseases by avoiding outdoor activities during peak biting activity periods.

In our studies, we used BG-Sentinel 2 traps and monitored them every hour, twenty-four hours a day over 96 hours, a method with some similarities to that used by Smith et al. ${ }^{7}$. In the past, diel biting activity studies were carried out using human landing catches following the methods primarily established by Haddow ${ }^{22}$. To our knowledge, only two studies have previously used sampling procedures not based on human landing catches to study the biting activity patterns of Ae. aegypti, the study by Ortega-Lopez et al. ${ }^{6}$ used mosquito electrocuting traps, and the study by Smith et al. ${ }^{7}$ used a mechanical rotator mosquito trap. In the present study, the use of BG-Sentinel II traps had the advantage that it was specifically designed to capture female host-seeking Ae. aegypti ${ }^{8,9}$. In addition, attached BG-Counter devices can keep track of the number of mosquitoes captured per specified unit time and environmental conditions, and store the information in a cloud server. However, the BG-Sentinel 2 traps collected a wide variety of mosquito species, (Table 1), and to keep track of specific species captured each hour, we had to monitor them every hour.

Overall, we present data on the diel activity of Ae. aegyptipopulations in two cities in the southern United States. In both cities the activity patterns were bimodal; there were peaks of activity in the mornings and the evenings. The significance of these observations is that these peaks can be targeted to improve the effectiveness of adulticide treatments aimed at controlling Ae. aegypti adult populations. Using BGSentinel 2 traps eliminates individual variations associated with human landing catches and the associated danger of infections from wild mosquitoes especially during ongoing outbreaks.

\section{Methods}

\section{Study Sites}

Miami, FL $\left(25.7617^{\circ} \mathrm{N}, 80.1918^{\circ} \mathrm{W}\right)$ and Brownsville, Texas $\left(25.9017^{\circ} \mathrm{N}, 97.4975^{\circ} \mathrm{W}\right)$ were selected as study sites, these cities have a history of $A e$. aegypti arboviral outbreaks ${ }^{17-21}$. Four study sites were selected in each city (Figure 5). All sites were in front or back yards in private homes and selected after obtaining permission from the owners.

\section{Sample collection}

We used BG-Sentinel-2 traps (Biogents AG, Regensburg, Germany) equipped with BG Counters (Biogents $A G$, Regensburg, Germany). The traps were baited with BG Lures and dry ice as a source of carbon dioxide ${ }^{23,24}$. These traps were used as substitutes for human hosts, they use lures which are blends of mosquito attractants consisting of lactic acid, ammonia, and caproic acid, substances which are also found on human skin ${ }^{8}$. The lures imitate human odor and the carbon dioxide imitates human breath. 
Owing to the lack of automatic collecting devices for BG-Sentinel traps, the traps were physically monitored every hour for 96 hours (4 days) at each location once every month from May to November 2019. Because of workforce limitations we did not have field teams dedicated to specific traps, rather a single team visited all four traps to collect the mosquitoes captured and reset each trap once every hour. Trap 1 (site 1) was monitored at the top of the hour, trap 2 (site 2) at 15 minutes past the hour, trap 3 (site 3 ) at 30 minutes past the hour and trap 4 (site 4 ) at 45 minutes past the hour. To accomplish this the field crews worked either in 12-hour shifts (two teams) or eight-hour shifts (three teams). On each visit, the BG-Sentinel collection bag was removed from the trap and replaced with a fresh one. The removed bag was placed into a gallon ziplock bag labeled with the trap site and the collection time and taken to the lab on ice in a cooler. In the lab, the mosquitoes were identified to species on chill tables by using the keys of Darsie and Ward ${ }^{25}$, placed in labeled cryovials, and shipped on dry ice to the CDC lab in Fort Collins, CO for arbovirus testing. The species and number of mosquitoes collected were recorded on Excel spreadsheets.

In June, two traps (one in Miami and one in Brownsville) resulted in low Ae. aegypti catch so they were relocated to more productive sites within the same neighborhood to better evaluate diel activity patterns. Trapping was conducted from May 2019 through November 2019. On each sampling, trap data was collected hourly for 4 days (96 hours). In Miami, collections were conducted from 5/7/19 to 5/11/19, $6 / 3 / 19$ to $6 / 7 / 19,7 / 7 / 19$ to $7 / 11 / 19,8 / 4 / 19$ to $8 / 7 / 19,9 / 3 / 19$ to $9 / 7 / 19,10 / 6 / 19$ to $10 / 10 / 19$, and $11 / 11 / 19$ to $11 / 14 / 19$. In Brownsville, collections were conducted $5 / 21 / 19$ to $5 / 23 / 19,6 / 13 / 19$ to $6 / 16 / 19,7 / 21 / 19$ to $7 / 25 / 19,8 / 18 / 19$ to $8 / 21 / 19,9 / 15 / 19$ to $9 / 19 / 19,10 / 7 / 19$ to $10 / 11 / 19$ and $11 / 22 / 19$ to $11 / 27 / 19$.

\section{Data Analysis}

The data within trap locations were considered the unit identifier in a Multi-level Multi-variable Longitudinal Model. The repeated measure was time in hours within each trap location*date. Then, we used the GLIMMIXED in SAS 9.4 and transformed the data as $\log ($ Aedes aegypti +1$)$ with a generalized Poisson estimator and log link with only linear time and no random intercept as the random effect. The covariates Linear Time*City*Season and Linear Time* Trap Location*City*Season were not significant and were removed from the model. We then used a multivariate analysis to analyze peak differences in the data, days with no peaks were removed and the morning peak (before 1500 hours) and evening peak (after 1500 hours) were analyzed separately using the Peak Start Time and Peak Max using the peak detection and measurement spreadsheet (available at:

https://terpconnect.umd.edu/ toh/spectrum/PeakFindingandMeasurement.htm).

\section{Declarations}

Acknowledgements 
We thank the following for assistance with the eight and 12 hours shifts monitoring mosquito traps and assitatnce in the laboratory, in Miami, Florida: Melissa Anderson, Yadira Diaz, Teresa Belledent, Johana Medina, and in Brownsville, Texas: Ester Carbajal, Francisco Reyes, Fernando Arellano Jr, Carolina Karavasilis, Pedro Montana, Maria Torres, Xochitl Estrada, Thalía Ríos, Jeremy Marshall and Edwin Valdez. This work was supported in part by Cooperative Agreement Number U01CK000512 and 1U01CK000510-05, funded by the Centers for Disease Control and Prevention. This work was also supported by the Miami-Dade Mosquito Control Division, the City of Brownsville Department of Public Health, Southeastern Regional Center of Excellence in Vector-Borne Diseases and the Gateway Program. Its contents are solely the responsibility of the authors and do not necessarily represent the official views of the Centers for Disease Control and Prevention or the Department of Health and Human Services.

\section{Author contributions}

J.P.M., C.V., G.L.H. and C.J.V., conceived of and designed the study. E.O., C.V., A.C., H.P., J.R., F.B., J.J., M.M., and J.P.M. were responsible for the mosquito collection and taxonomic identification. J.P.M. and G.L.H. developed the study methodology. A.B.B.W., G.C., J.C.B. and J.P.M. developed the data analysis methodologies. J.P.M., A.R., W.D.P., C.V., H.P., G.L.H. and C.J.V. were responsible for the implementation of the study. A.B.B.W., G.C., and J.P.M. compiled and analyzed the data and prepared the original figures. J.P.M. wrote the original draft of the paper. All authors contributed to reviewing and editing the paper. J.P.M., C.V., and H.P. were responsible for the project administration and supervision.

\section{References}

1. Christophers, S. R. Aedes aegypti (L) the Yellow Fever Mosquito: Life History, Bionomics and Structure. Cambridge University Press (1960).

2. Lumsden W. H. R. The activity cycle of domestic Aedes (Stegomyia) aegypti (L.) (Diptera, Culicidae) in Southern Province, Tanganyika. Bull Ent Res 48, 769-782 (1957)

3. Trpis M., McClelland G. A. H., Gillett J. D., Teesdale C., Rao T. R. Diel periodicity in the landing of Aedes aegypti on man. Bull. Wld. Hlth. Org. 48, 623-629 (1973).

4. Chadee D. D., Martinez R. Landing periodicity of Aedes aegypti with implications for dengue transmission in Trinidad, West Indies. J Vector Ecol. 25, 158-163 (2000).

5. Diarrassouba S., Dossou-Yovo J. Atypical activity rhythm in Aedes aegypti in a sub-Sudanian savannah zone of Côte d'Ivoire. Bull. Soc. Pathol. Exot. 90, 361-363. (1997).

6. Ortega-López L. D., Pondeville E., Kohl A., León R., Betancourth M. P., Almire F., Sergio Torres-Valencia S., Saldarriaga S., Mirzai N., Ferguson H. M. The mosquito electrocuting trap as an exposure-free method for measuring human-biting rates by Aedes mosquito vectors. Parasites and Vectors 13,31 (2020). https://doi.org/10.1186/s13071-020-3887-8.

7. Smith M., Dixon D., Bibbs C., Autry D., Xue R. D. Diel patterns of Aedes aegypti (Diptera: Culicidae) after resurgence in St. Augustine, Florida as collected by a mechanical rotator trap. J. Vector Ecol. 43, 201-204 (2018). 
8. Krockel U., Rose A., Eiras A. E., Geier M. New tools for surveillance of adult yellow fever mosquitoes: comparison of trap catches with human landing rates in an urban environment. J. Am. Mosq. Control Assoc. 22, 229-238 (2006).

9. Maciel-de-Freitas R., Eiras A. E., Lourenço-de-Oliveira R. Field evaluation of effectiveness of the BGSentinel, a new trap for capturing adult Aedes aegypti (Diptera: Culicidae). Mem. Inst. Oswaldo Cruz 101, 321-325 (2006).

10. McClelland G. A. H. Observations on the mosquito, Aedes (Stegomyia) aegypti (L.) in East Africa I. The biting cycle in an outdoor population at Entebbe, Uganda. Bull. Entomol. Res. 50, 227-235 (1959).

11. Boorman M. A. Studies on the biting habits of the Mosquito Aedes (Stegomyia) aegypti Lin., in a West Africa village. W. Af.r Med. J. 9, 111-122 (1960).

12. Diouf G., Seck M. T., Ciss M., Faye B., Biteye B., Bakhoum M. T., Fall A. G. Improving the efficiency of the BG sentinel 2 trap to assess the activity of Aedes (Stegomyia) aegypti [Linnaeus, 1762] in Senegal. Acta Tropica 222, 106065 (2021)

13. McClelland G. A. H. Observations on the mosquito Aedes (Stegomyia) aegypti (L.) in East Africa II. The biting cycle in a domestic population on the Kenya Coast. Bull. Entomol. Res. 50, 687-696. (1960).

14. Rogers D. J , Wilson A. J., Hay S. I., Graham A. J. The global distribution of yellow fever and dengue. Adv. Parasitol. 62, 181-220. (2006).

15. Bhatt S., Gething P. W., Brady O. J., Messina J. P., Farlow A. W., Moyes C. L., Drake J. M., Brownstein J. S., Hoen A. G., Sankoh O., Myers M. F., George D. B., Jaenisch T., Wint G. R., Simmons C. P., Scott T. W., Farrar J. J., Hay S. I. The global distribution and burden of dengue. Nature. 496, 504-507 (2013).

16. McAllister J. C., Porcelli M., Medina J. M., Delorey M. J., Connelly C. R., Godsey M. S., Panella N. A., Dzuris N., Boegler K. A., Kenney J. L., Kothera L., Vizcaino L., Lenhart A. E., Mutebi J. P., Vasquez C. Mosquito control activities during local transmission of Zika virus, Miami-Dade County, Florida, USA, 2016. Emerg. Infect. Dis. 26, 881-890 (2020).

17. Ramos M. M., Mohammed H., Zielinski-Gutierrez E., Hayden M. H., Lopez J. L. R., Fournier M., Trujillo A. R., Burton R., Brunkard J. M., Anaya-Lopez L. Epidemic dengue and dengue hemorrhagic fever at the Texas-Mexico border: results of a household-based seroepidemiologic survey, December 2005. Am. J. Trop. Med. Hyg., 78, 364-369 (2008).

18. Likos A., Griffin I., Bingham A. M., Stanek D., Fischer M., White S., Hamilton J., Eisenstein L., Atrubin D., Mulay P., Scott B., Jenkins P., Fernandez D., Rico E., Gillis L., Jean R., Cone M., Blackmore C., McAllister J., Vasquez C., Rivera L., Philip C. Local mosquito-borne transmission of Zika virus Miami-Dade and Broward Counties, Florida, June-August 2016. Morb. Mortal. Wkly. Rep. 65, 10321038 (2016).

19. Duffy J. Yellow Fever in the Continental United States During the Nineteenth Century. Bull NY Acad. Med. 44, 687 - 701 (1968). 
20. Adalja A. A., Sell T. K., Bouri N, Franco C. Lessons learned during dengue outbreaks in the United States, 2001-2011. Emerg Infect Dis. 18, 608-614. (2012).

21. Bouri N., Sell T. K., Franco C., Adalja A. A., Henderson D. A., Hynes N. A. Return of epidemic dengue in the United States: implications for the public health practitioner. Public Health Rep. 127, 259-266 (2012).

22. Haddow A. J. Studies of the biting habits of African mosquitoes. An appraisal of methods employed, with special references to the twenty-four hour catch. Bull. Entomol. Res. Bull. 45, 199-242 (1954).

23. Ázara T. M. F.d., Degener C. M., Roque R. A., Ohly J. J., Geier M., Eiras A. E. The impact of $\mathrm{CO}_{2}$ on collection of Aedes aegypti (Linnaeus) and Culex quinquefasciatus Say by BG-Sentinel (R) traps in Manaus Brazil. Mem. Inst. Oswaldo Cruz, 108, 229-232 (2013).

24. Wilke A. B. B., Carvajal A., Medina J., Anderson M., Nieves V. J., Ramirez M., Vasquez C., Petrie W., Cardenas G., Beier J. C. Assessment of the effectiveness of BG-Sentinel traps baited with $\mathrm{CO}_{2}$ and BG-Lure for the surveillance of vector mosquitoes in Miami-Dade County, Florida. PLoS One 22,14(2):e0212688. doi: 10.1371/journal.pone.0212688 (2019).

25. Darsie Jr. R. F., Ward R. A. Identification and geographic distribution of the mosquitoes of North America, North of Mexico. $2^{\text {nd }}$ eds. Florida: University Press Publishing (2005).

\section{Figures}



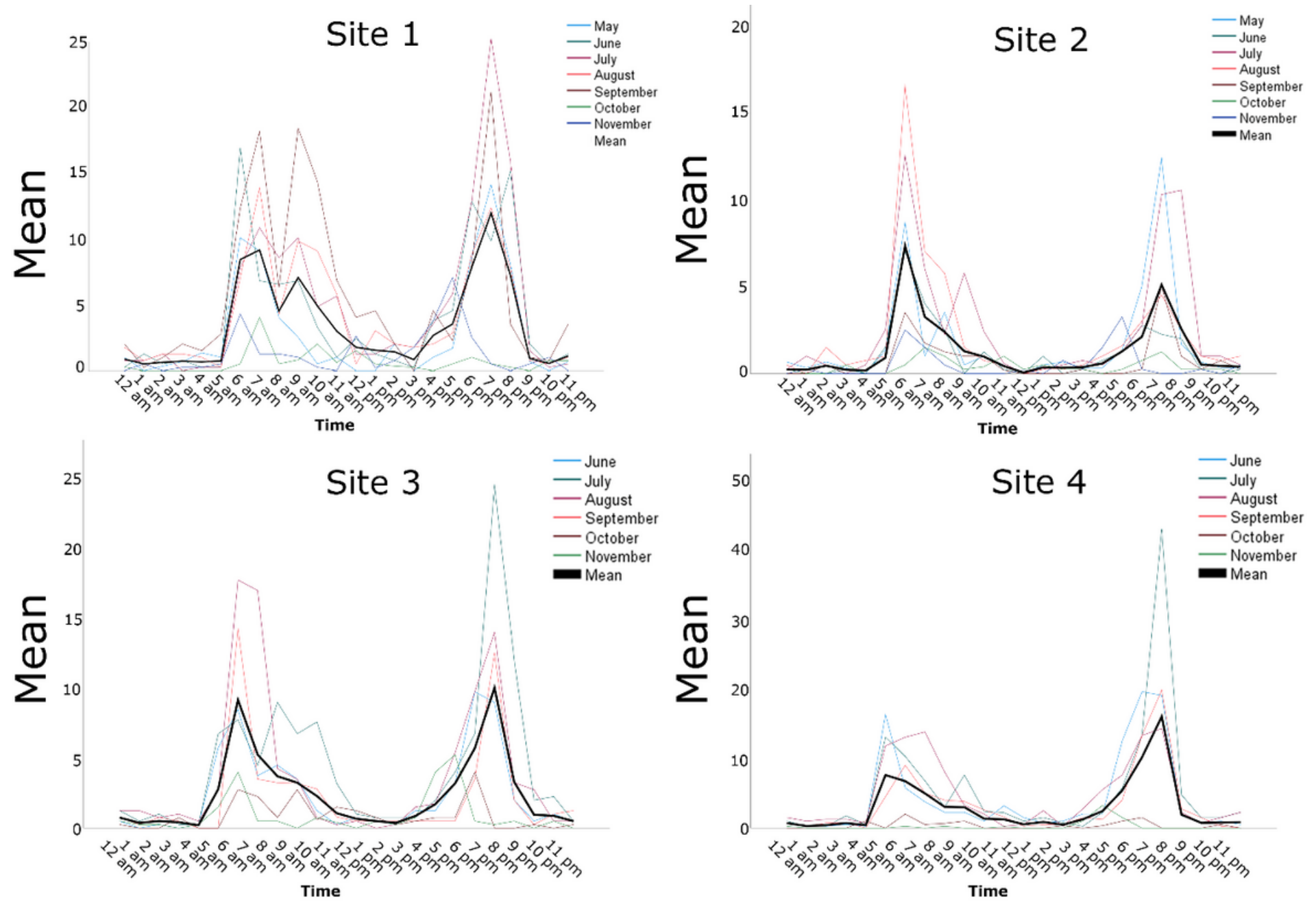

Figure 1

Diel activity patterns for Ae. aegypti populations at each of the 4 sampling sites in Miami, Florida. "Mean" on the graphs represent the mean number of female Ae. aegypti mosquitoes captured per trap/hour. The thick black line is the mean number of Ae. aegypti female mosquitoes captured per trap/hour throughout the study period from May to November 2019. 

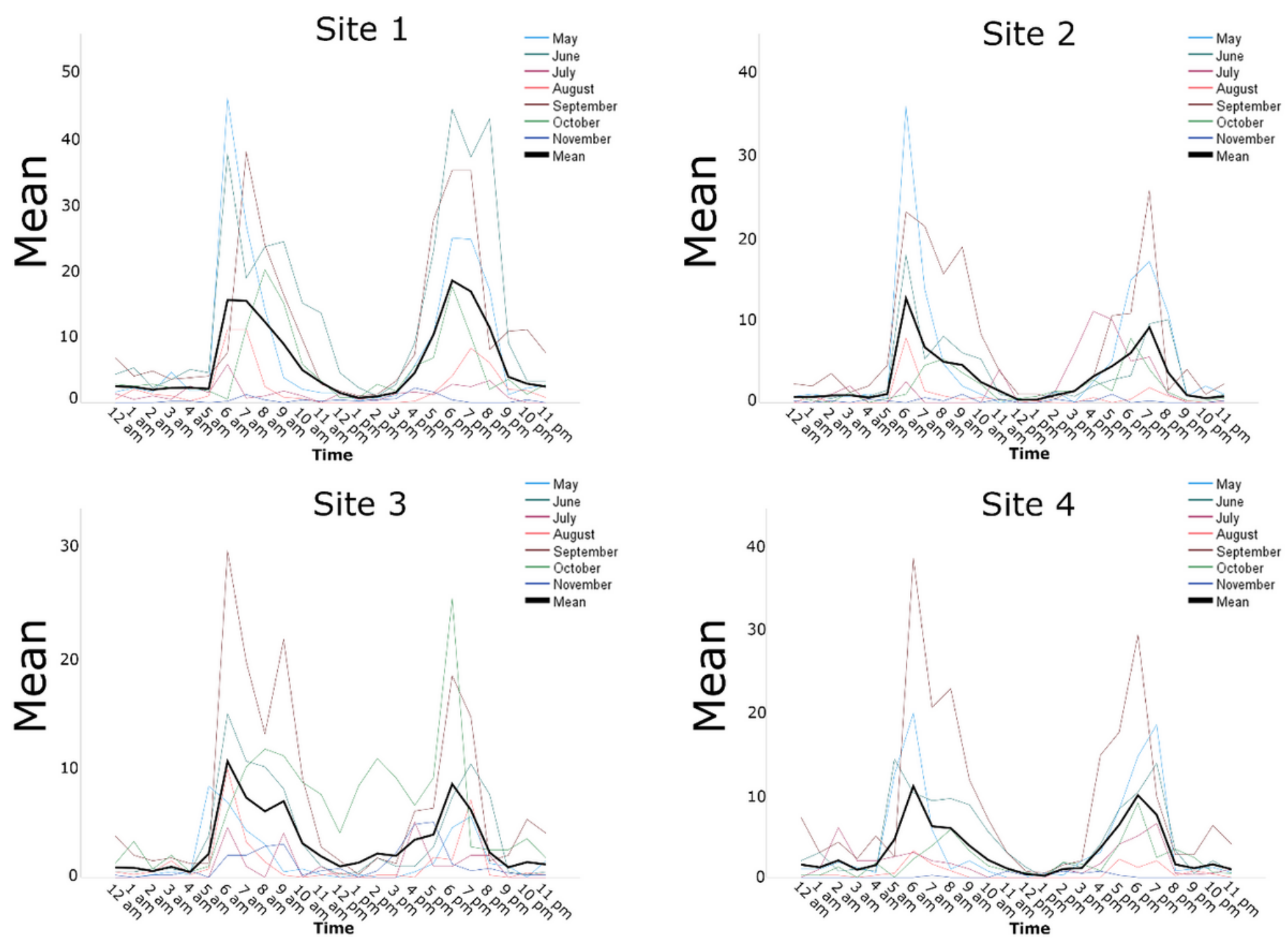

Figure 2

Diel activity patterns for Ae. aegypti populations at each of the 4 sampling sites in Brownsville, Texas. "Mean" on the graphs represent the mean number of female Ae. aegypti mosquitoes captured per trap/hour. The thick black line is the mean number of Ae. aegypti female mosquitoes captured per trap/hour throughout the study period from May to November 2019. 
Number Collected Per Trap/Hour

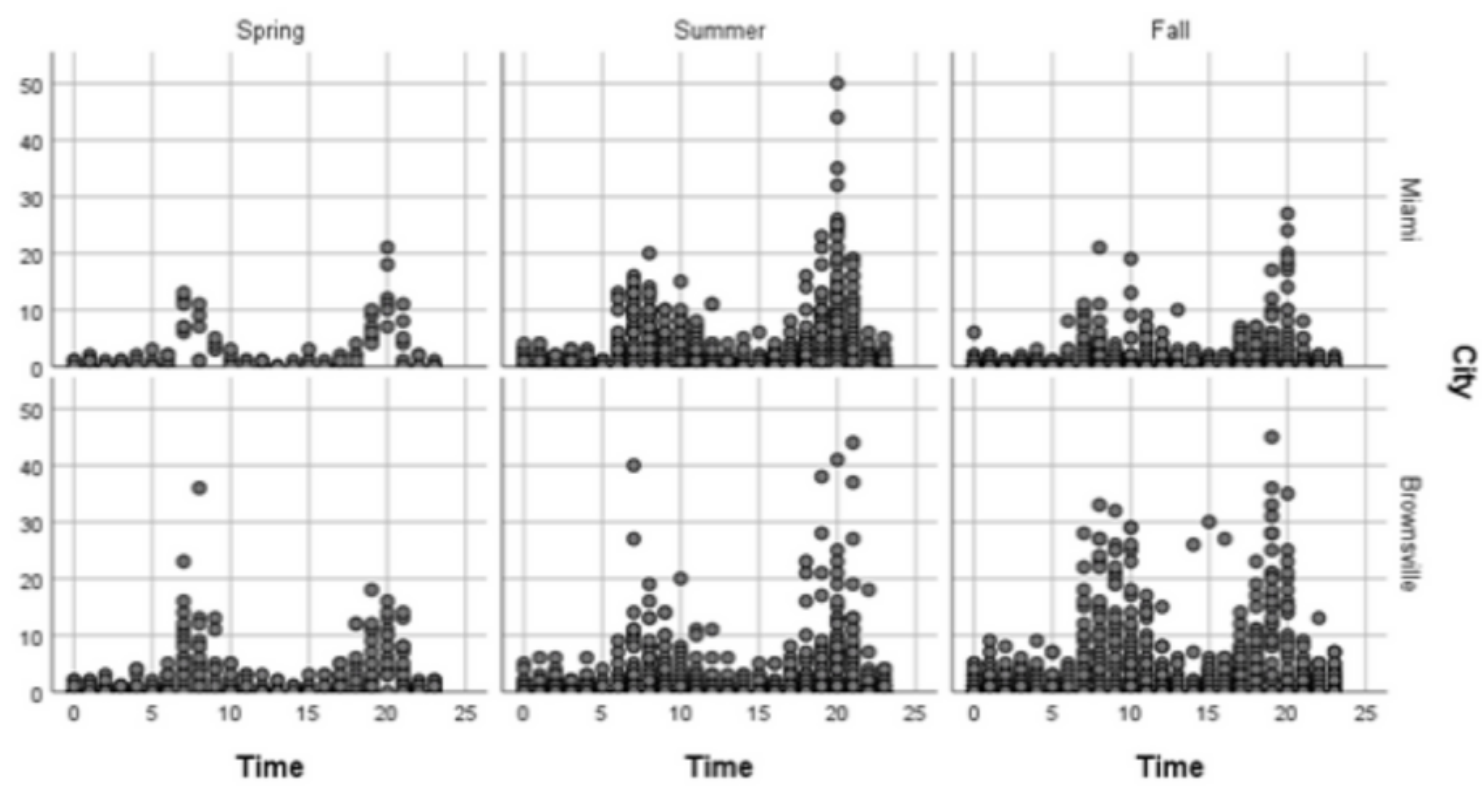

\section{Figure 3}

Diel activity patterns of Ae. aegypti in different seasons (Spring March - June, Summer June September, Fall September - December). The y axis is the relative abundance of female Ae. aegypti, the number of female Ae. aegypti captured per trap/hour at all sites in each city. 


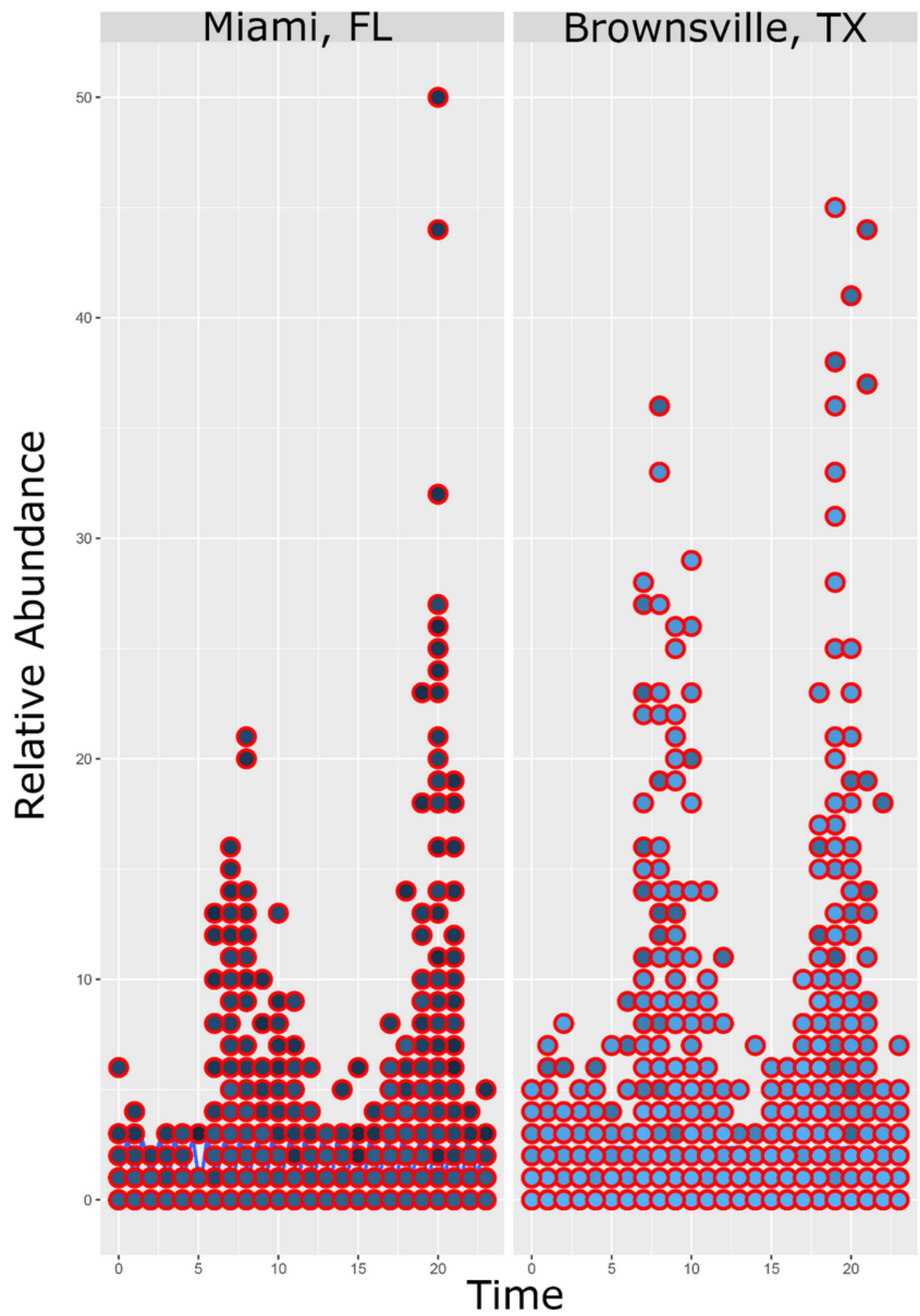

Figure 4

Diel activity patterns of female Ae. aegypti mosquitoes in Miami, Florida and Brownsville, Texas. Relative abundance on the $y$ axis represents the relative abundance of female Ae. aegypti mosquitoes captured per trap per hour throughout the sampling period, May through November 2019. 
A

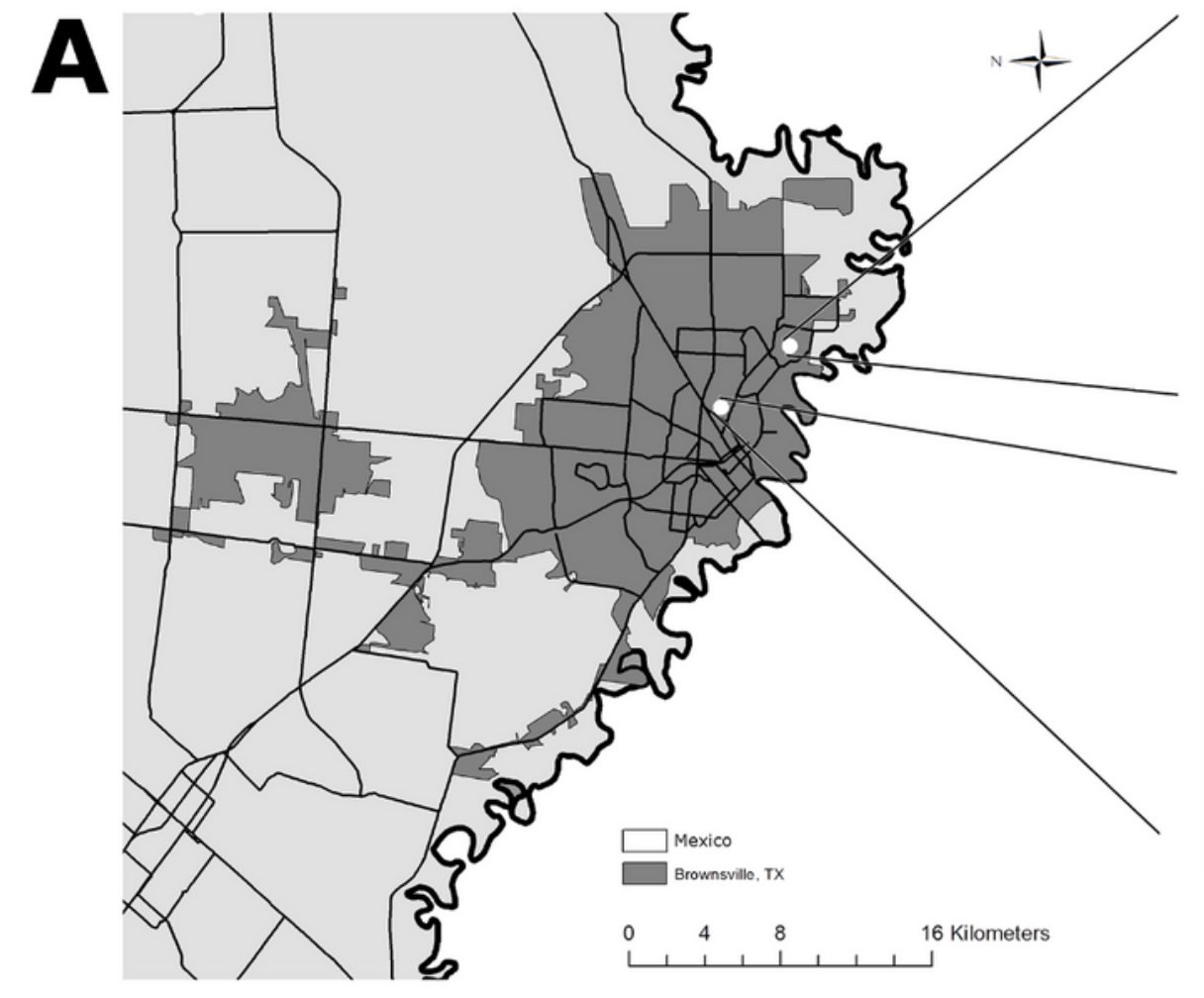

B

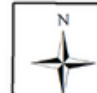

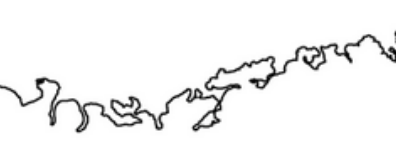
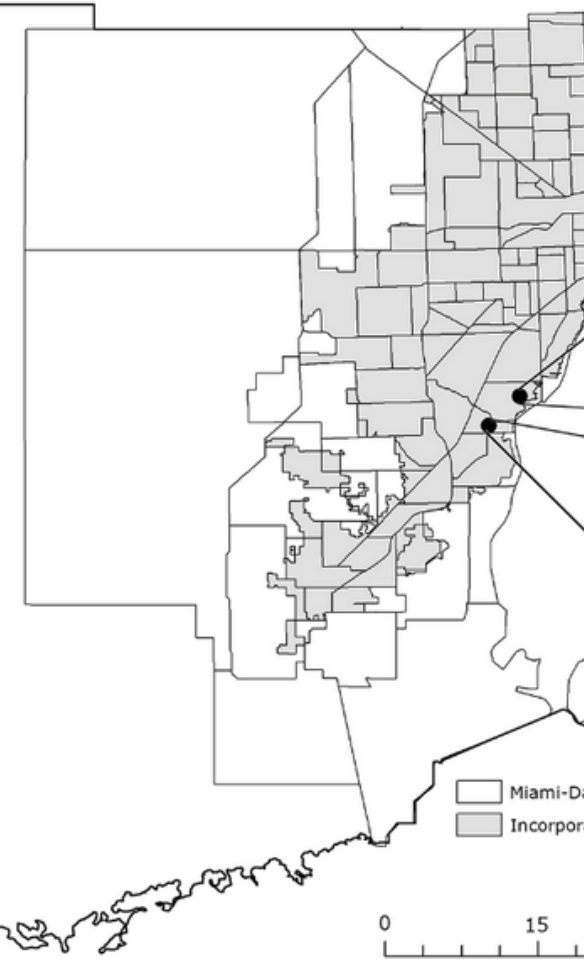
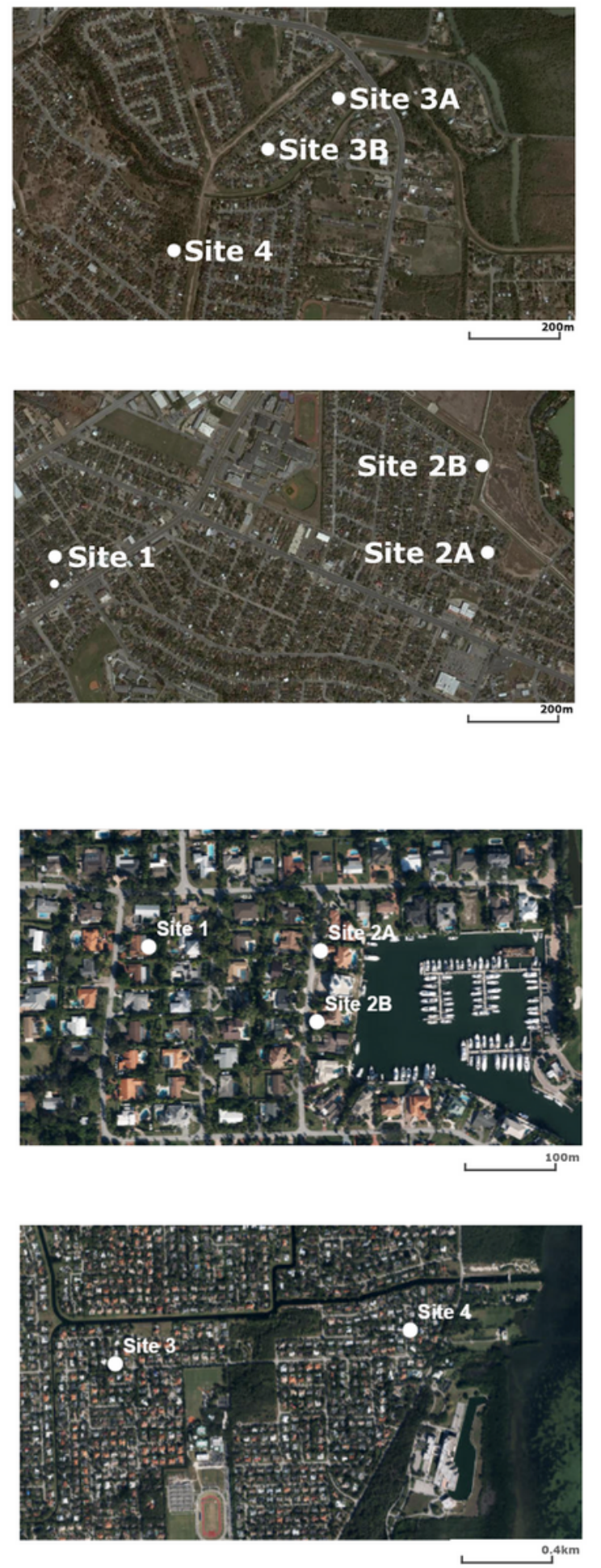

\section{Figure 5}

Maps of sampling sites in Brownsville, Texas (A) and Miami Dade County, Florida, (B). In Brownsville, the traps were moved from $2 \mathrm{~A}$ to $2 \mathrm{~B}$ and from $3 \mathrm{~A}$ to $3 \mathrm{~B}$ because mosquito catched dipped markedly at sites $2 \mathrm{~A}$ and $3 \mathrm{~A}$. The traps were moved to the more productive sites $2 \mathrm{~B}$ and $3 \mathrm{~B}$. In Miami, the trap was moved from site $2 \mathrm{~A}$ to site $2 \mathrm{~B}$ for the same reason as in Brownsville. 